National Center for Family \& Marriage Research

@ Bowling Green State University

Family Profile No. 3, 2022

\title{
High School Seniors' Attitudes Toward Cohabitation as a Testing Ground for Marriage, 2020
}

Author: Adrianne R. Brown

The share of couples who cohabit prior to marriage has increased over time. Among marriages that took place between 2015 and 2019, three quarters were preceded by cohabitation, up from only one-third in the mid-to-late 70s (FP-21-04). This shift in behavior has been accompanied by a shift in attitudestoward cohabitation. Using Monitoring the Future data, this profile examines change in high school seniors' attitudes toward cohabitation as a testing ground for marriage from 1976 to 2020 . This measure is based on agreement or disagreement (neutral responses are not shown) with the statement "It is usually a good idea for a couple to live together before getting married in order to find out whether they really get along." This profile updates previous profiles on high school seniors' attitudes toward cohabitation using the most recent available data (FP-19-10; FP-16-13), and is a companion profile to High School Seniors' Expectations to Marry, 2020 (

\section{Attitudes Toward Cohabitation as a Testing Ground for Marriage Over Time}

- The share of high school seniors who agreed with the notion of cohabitation as a testing ground for marriage increased from four out of ten (40\%) in 1976 to seven out of ten (69\%) in 2020.

- The share who disagreed with cohabitation as a testing ground for marriage decreased from 44\% in 1976 to just $15 \%$ in 2020.
Figure 1. High School Seniors' Attitudes Toward Cohabitation as a Testing Ground for Marriage, 1976-2020

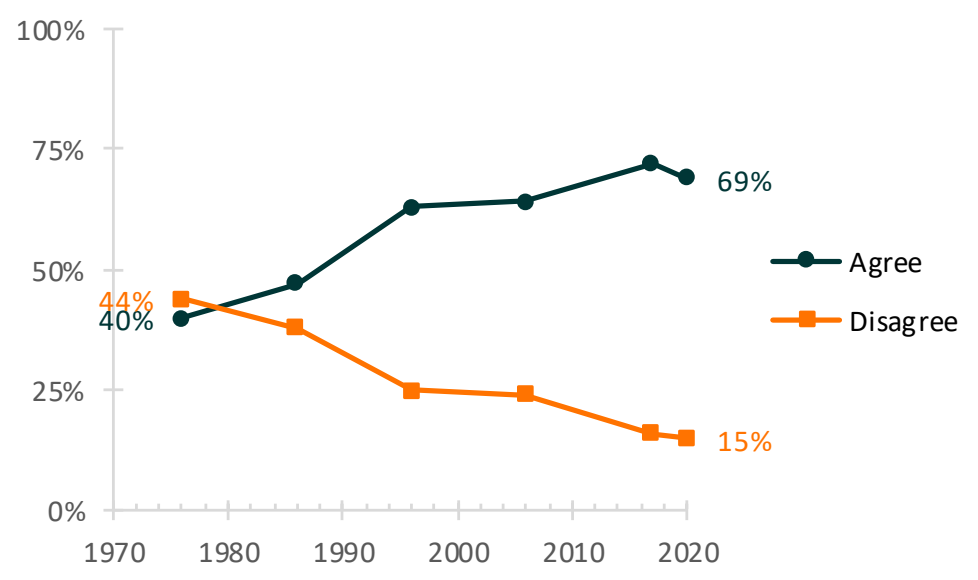

Source: NCFMR calculations of Monitoring the Future, 19762020

Attitudes Toward Cohabitation as a Testing Ground for Marriage by Parental Educational Attainment

Figure 2. High School Seniors' Agreement with Cohabitation as a Testing Ground for Marriage by Parental Educational

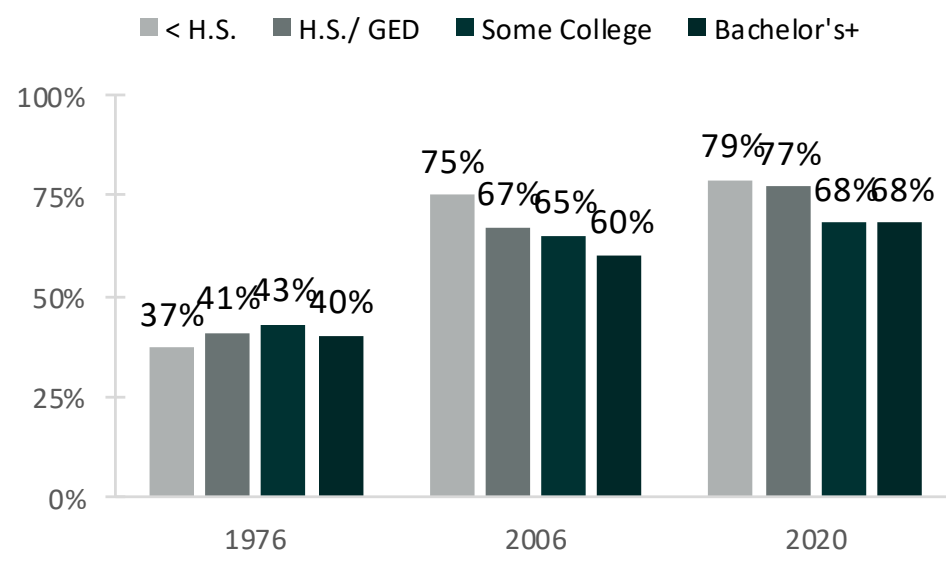

Source: NCFMR calculations of Monitoring the Future, 19762020
- The share of high school seniors who agreed with cohabitation as a testing ground for marriage increased across all four categories of parental educational attainment between 1976 and 2020.

- In 1976, the share of those who agreed that cohabitation as a testing ground for marriage was a good idea was smallest among those whose parents had less than a high school diploma (37\%). In both 2006 and 2020, the share who agreed with cohabitation was largest among this group ( $75 \%$ and $79 \%$, respectively).

- In 2020, those whose parents had some college education and those whose parents had completed college had the smallest shares who agreed with cohabitation as a testing ground for marriage (68\% for both). 
- In 1976 and 2006, larger shares of men than women agreed with cohabitation as a testing ground for marriage. By 2020, a larger share of women than men agreed with this view.

- In 1976, about half of men (48\%) and one third of women $(33 \%)$ agreed with cohabitation as a testing ground for marriage. In 2020, over two thirds of men and women agreed with cohabitation $(68 \%$ among men and $70 \%$ among women).
Figure 3. High School Seniors' Agreement with Cohabitation as a Testing Ground for Marriage by Gender, 1976, 2006, and 2020

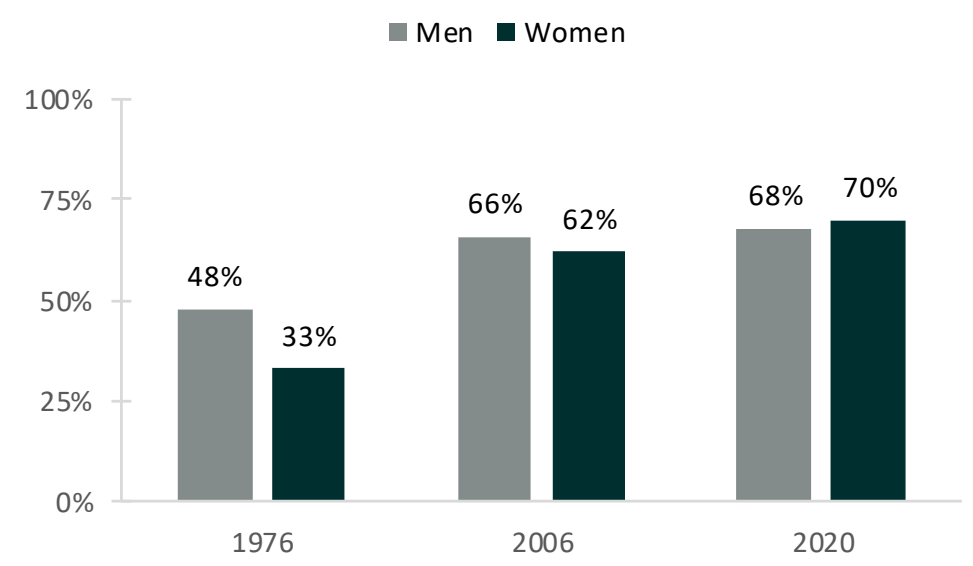

Source: NCFMR calculations of Monitoring the Future, 19762020

\section{Attitudes Toward Cohabitation as a Testing Ground for Marriage by Race/Ethnicity}

Figure 4. High School Seniors' Agreement with Cohabitation as a Testing Ground for Marriage by Race/Ethnicity, 2006 and 2020*

$$
\text { White Black } \mathbf{\square} \text { Hispanic }
$$

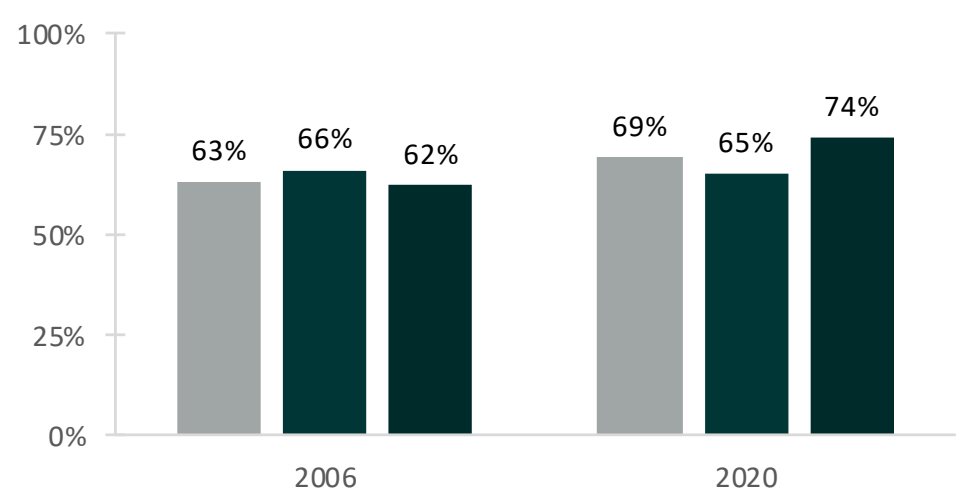

Source: NCFMR analyses of Monitoring the Future, 2006 \& 2020

* Prior to 2005, the Monitoring the Future data only indicated whether the res pondent identified as White or Non-White, therefore 1976 is not included in this figure/analysis.
- In 2006, there was little variation by race/ethnicity in agreement with cohabitation as a testing ground for marriage. The share of Black students who agreed with this notion (66\%) was slightly higher than the share of White and Hispanic students who agreed (63\% and 62\%, respectively).

- By 2020 , nearly three quarters (74\%) of Hispanic students agreed with cohabitation as a testing ground for marriage compared to $69 \%$ of White students and $65 \%$ of Black students.

\section{Data Source:}

Miech, R. A., Johnston, L. D., Bachman, J. G., O'Malley, P. M., Schulenberg, J. E., a nd Pa trick, M. E. (2021) Monitoring the Future: A continuing study of American youth (12th-Grade Survey), 2020 (ICPSR 38156.v1) [Data set]. National Addiction \& HIV Data Archive Program. https://doi.org/10.3886/ICPSR38156.v1

\section{References:}

Manning, W. D. \& Carlson, L. (2021). Trends incohabitation prior to ma rriage. Family Profiles, FP-21-04. Bowling Green, OH: National Center for Fa mi ly \& Marriage Res earch. https://doi.org/10.25035/ncfmr/fp-21-04

\section{Suggested Citation:}

Brown, A. R. (2022). High school seniors' attitudes toward cohabitation as a testing ground for marriage, 2020. Family Profiles, FP22-03. Bowling Green, OH: National Center for Family \& Marriage Research. https://doi.org/10.25035/ncfmr/fp-22-03 